\title{
Unusual cause of saddle nose
}

\author{
Ella Starobinska, ${ }^{1}$ Muhsen Al-ani, ${ }^{2}$ Yasir Abdulqader, ${ }^{2}$ Konstantinos Parperis ${ }^{2}$
}

IInternal Medicine, Banner University Medical Center, Tucson, Az, USA ${ }^{2}$ Internal Medicine, Maricopa Medical Center, Phoenix Arizona, USA

Correspondence to Dr Ella Starobinska, elstar@email.arizona.edu

Accepted 5 October 2017
CrossMark

To cite: Starobinska $\mathrm{E}$ Al-ani M, Abdulqader $Y$, et al. BMJ Case Rep Published Online First: [please include Day Month Year] doi:10.1136/bcr-2017221004

\section{DESCRIPTION}

A 53-year-old female presented with a 2-week history of shortness of breath, cough and fever. Over the past 6 months, she reported painful tongue ulcers and pain in her nose, accompanied with nasal crusting and yellowish discharge. She had a history of pulmonary coccidioidomycosis, diagnosed 10 years ago, and she was treated with antifungal regimen. Physical examination revealed rhonchi bilaterally, multiple shallow ulcerative lesions on her tongue and a saddle nose deformity (figure 1A). CT of the chest demonstrated extensive ground-glass opacities with areas of nodular consolidation. Given her symptoms and history of coccidioidomycosis, nasal cavity biopsy was performed that revealed focal ulceration, non-specific inflammation with many cocci spherules, confirmed by Grocott's methenamine silver stain (figure 1B). Cultures from the lesions and the sputum grew Coccidioides immitis. Treatment with fluconazole $400 \mathrm{mg}$ daily was initiated, and after several days her symptoms improved.

C. immitis is a pathogenic dimorphic fungus responsible for causing coccidioidomycosis, an infection that commonly affects the lungs and less often the skin. ${ }^{1}$

The clinical spectrum of the cutaneous lesions varies from papules, nodules, gummas, acneiform pustular lesions and abscesses. ${ }^{2}$ Our patient presented with disseminated coccidioidomycosis with pulmonary and skin involvement that caused chronic nasal cartilage inflammation, which we believe to be the first case

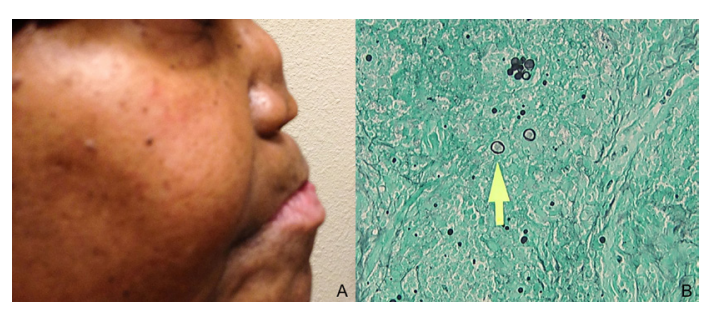

Figure 1 (A) Photograph of the patient showing the saddle nose, side view. (B) Microscopic picture from the nasal skin biopsy, yellow arrow pointing to the cocci spherule, magnification $\times 400$.

\section{Learning points}

- The main causes for saddle nose include trauma, granulomatosis with polyangiitis, relapsing polychondritis, intranasal cocaine use, malignancies, syphilis, Crohn's disease and lepromatous leprosy.

- Coccidiodomycosis often manifests with pulmonary involvement and less often cutaneous involvement. However, here we report the first case of saddle nose secondary to coccidioidomycosis.

report of saddle nose due to coccidioidomycosis. The most common cause for saddle nose is trauma, but the deformity can also be a feature of granulomatosis with polyangiitis, relapsing polychondritis, intranasal cocaine use, malignancies, syphilis, Crohn's disease and lepromatous leprosy. ${ }^{3}$

Contributors ES involved in managing the patient, writing parts for the final version of the manuscript, have read and approved the final version submitted and completed submission process. $M A$ and $Y A$ involved in managing the patient, writing parts for the final version of the manuscript and have read and approved the final version submitted. KP is a supervising attending physician managing the patient, collecting data, writing parts for the final version of the manuscript and have read and approved the final version submitted.

Competing interests None declared.

Patient consent Obtained.

Provenance and peer review Not commissioned; externally peer reviewed.

(c) BMJ Publishing Group Ltd (unless otherwise stated in the text of the article) 2017. All rights reserved. No commercial use is permitted unless otherwise expressly granted.

\section{REFERENCES}

1 Stockamp NW, Thompson GR. Coccidioidomycosis. Infect Dis Clin North Am 2016;30:229-46.

2 Welsh 0, Vera-Cabrera L, Rendon A, et al. Coccidioidomycosis. Clin Dermatol 2012;30:573-91.

3 Schreiber BE, Twigg S, Marais J, et al. Saddle-nose deformities in the rheumatology clinic. Ear Nose Throat J 2014;93:E45-7.

Copyright 2017 BMJ Publishing Group. All rights reserved. For permission to reuse any of this content visit

http://group.bmj.com/group/rights-licensing/permissions.

BMJ Case Report Fellows may re-use this article for personal use and teaching without any further permission.

Become a Fellow of BMJ Case Reports today and you can:

- Submit as many cases as you like

- Enjoy fast sympathetic peer review and rapid publication of accepted articles

- Access all the published articles

- Re-use any of the published material for personal use and teaching without further permission

For information on Institutional Fellowships contact consortiasales@bmjgroup.com

Visit casereports.bmj.com for more articles like this and to become a Fellow 